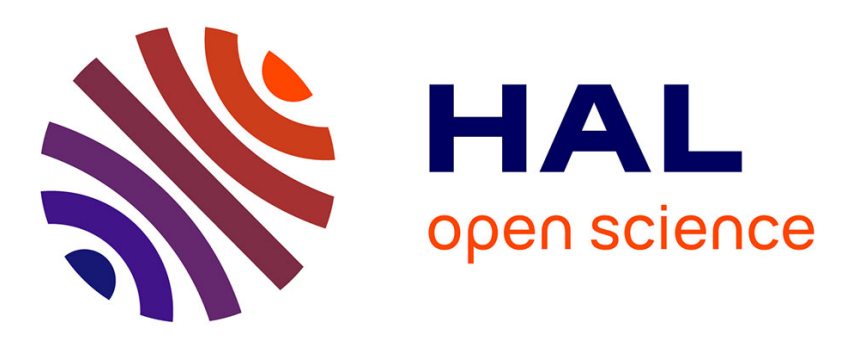

\title{
Tren-Capped Hexaphyrin Zinc Complexes: Interplaying Molecular Recognition, Möbius Aromaticity, and Chirality
}

Hervé Ruffin, Gildas Nyame Mendendy Boussambe, Thierry Roisnel, Vincent Dorcet, Bernard Boitrel, Stéphane Le Gac

\section{To cite this version:}

Hervé Ruffin, Gildas Nyame Mendendy Boussambe, Thierry Roisnel, Vincent Dorcet, Bernard Boitrel, et al.. Tren-Capped Hexaphyrin Zinc Complexes: Interplaying Molecular Recognition, Möbius Aromaticity, and Chirality. Journal of the American Chemical Society, 2017, 139 (39), pp.13847-13857. 10.1021/jacs.7b07559 . hal-01617955

\section{HAL Id: hal-01617955 \\ https://hal-univ-rennes1.archives-ouvertes.fr/hal-01617955}

Submitted on 25 Oct 2017

HAL is a multi-disciplinary open access archive for the deposit and dissemination of scientific research documents, whether they are published or not. The documents may come from teaching and research institutions in France or abroad, or from public or private research centers.
L'archive ouverte pluridisciplinaire HAL, est destinée au dépôt et à la diffusion de documents scientifiques de niveau recherche, publiés ou non, émanant des établissements d'enseignement et de recherche français ou étrangers, des laboratoires publics ou privés. 


\section{INTRODUCTION}

Over the last two decades, the field of expanded porphyrins has grown quasi exponentially, offering an infinite playground to chemists. ${ }^{1}$ This family encompasses compounds featuring a smaller macrocyclic circuit (SMC) with more than 16 atoms (i.e. larger than that of a porphyrin), including skeleton variations such as pyrrole confusion, $\alpha-\alpha$ linked pyrroles.... Usually, expanded porphyrins exhibit "intriguing" properties, resulting from the strong interplay between their $\pi$-conjugated system, aromaticity, electronic features, redox states, flexibility/topology, coordination behavior, and reactivity. They offer precious tools to study the relationship between topology and aromaticity, a major breakthrough being the achievement of Möbius aromatic architectures. ${ }^{2,3}$ Expanded porphyrins also give new opportunities in the design of molecular switches and optoelectronic materials, and some members such as hexaphyrin [26] $\mathbf{H}^{2 \mathrm{~b}}$ have become benchmarks (Figure 1a, 26 $\pi$-conjugated species). Surprisingly, in strong contrast with porphyrins, molecular recognition remains an under-explored research area with their expanded congeners, and is somehow limited to anion recognition with sapphyrins and cyclo[8]pyrroles. ${ }^{4}$ Thus, combining the above mentioned intrinsic properties of expanded porphyrin frames with molecular recognition events is highly desired. Notably, bridging the gap between the core concepts associated to supra- molecular complexes (induced fit, complementarity, cooperativity...), ${ }^{5}$ which are ubiquitous to biological events, and Möbius twisted aromatic structures, ${ }^{2,3}$ which are unknown in Nature, is of fundamental interest.

To tackle this issue, we considered the synthesis of novel hexaphyrins capped with a tripodal metal binding site through a post-modification approach of an hexaphyrin platform (Figure 1c). This study was motivated (i) by our recent findings dealing with hexaphyrin-cyclodextrin hybrids (Figure 1b), ${ }^{6}$ whose hosting behavior can be tuned by a topological adaptation of the hexaphyrin; ${ }^{7}$ (ii) to probe efficient procedures for the "dressing" of hexaphyrins. Relatively to porphyrins, their expanded congeners suffer from less developed methods of preparation. More particularly, their functionalizations according to post-modification strategies are somehow limited, ${ }^{8-13}$ so that expanded porphyrins sorely lack molecular platforms that could be readily prepared and used as a starting material for the construction of sophisticated macrocyclic structures. In contrast, meso-tetra(2-aminophenyl)porphyrin (TAPP, Figure $1 \mathrm{a})^{14}$ is such a famous platform, extensively used for the introduction of various functional groups surrounding the $\mathrm{N}$ core cavity, notably for biomimetic, ${ }^{15}$ catalysis $^{16}$ or fundamental coordination purposes. ${ }^{17,18}$

Inspired by TAPP, we envisioned the synthesis of a related hexaphyrin platform, namely meso-tris(2-aminophenyl)hexaphyrin (Figure 1c), possessing a readily accessible 
$(\mathrm{AB})_{3}$-type meso-substitution pattern consistent with the grafting of tripodal units. Following this approach, we describe herein unprecedented hexaphyrin-based molecular hosts with the synthesis and coordination study of tris(2aminoethyl)amine (tren)-capped hexaphyrins.

\section{RESULTS}

The synthesis of the targeted hexaphyrin platform 2 was accomplished following a two-step procedure (Scheme 1). First, the trinitro precursor 1 was prepared by the methanesulfonic acid (MSA)-catalyzed condensation of 5-(2nitrophenyl)dipyrromethane with pentafluorobenzaldehyde in $\mathrm{CH}_{2} \mathrm{Cl}_{2}$, followed by oxidation with 2,3-dichloro-5,6dicyano-1,4-benzoquinone (DDQ) ${ }^{19}$ Compound 1 was isolated in its $26 \pi$ aromatic form as a deep purple solid with a $16 \%$ yield. The ${ }^{1} \mathrm{H}$ NMR spectrum corresponds to the sum of the NMR patterns of the various atropisomers in slow equilibrium at $298 \mathrm{~K}$ and below. At higher temperatures (above $330 \mathrm{~K}$ ), a single NMR pattern corresponding to a rectangular shape macrocycle with two central inverted pyrroles was observed (SI), deduced from characteristic regions for the in and out $\beta$-pyrrolic protons $(-2.15 \mathrm{ppm}$ and 8.90 to $9.35 \mathrm{ppm}$, respectively). These observations indicate that, as compare to the related TAPP, ${ }^{14 c}$ the energy barrier for the interconversion of the atropisomers of $\mathbf{1}$ is much lower, preventing their separation. The crystal structure of 1 revealed only one atropisomer with the meso-(2-nitrophenyl) group on the short side (Ar2) opposite to those on the long sides (Ar1 and Ar3), relative to the hexaphyrin mean plane (Figure 2). The reduction of the nitro groups of 1 was then attempted but revealed to be non-trivial. Indeed, usual methods as $\mathrm{SnCl}_{2} / \mathrm{HCl}$ failed, leading mainly to degradation products. We thus turned to a Pd catalyzed hydrogenation procedure. Mass spectrometry monitoring indicated complete reduction after $c a .24$ hours at $30^{\circ} \mathrm{C}$, with a $\mathrm{H}_{2}$ pressure of 80 bars and a catalytic amount of $\mathrm{Pd}(0) / \mathrm{C}$. Hexaphyrin 2 suffers from a lack of stability, likely due to

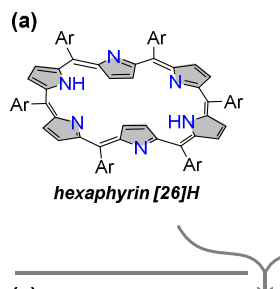

(c)

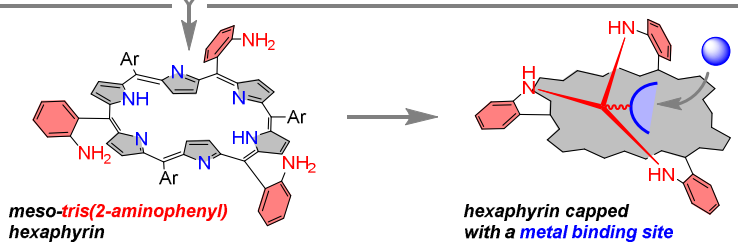

Figure 1. (a) Structures of the benchmark hexaphyrin [26]H and of the widespread TAPP platform. (b) Unique example of a triply-bridged hexaphyrin-cyclodextrin hybrid. (c) Global strategy of the present study to access first an hexaphyrin platform, and second hexaphyrins capped with a tripodal metal binding unit. $\mathrm{Ar}=\mathrm{C}_{6} \mathrm{~F}_{5}$. the electron donating character of the aniline function, ${ }^{20}$ preventing purification by silica gel chromatography. It is worth to note that reduction of the hexaphyrin core of 2 into its $28 \pi$ form also occurs during this process (vide infra). Compound 2 was therefore used without purification. Two different linkers were then introduced, by reacting 2 with either acryloyl chloride or 3-(chloromethyl)benzoyl chloride (Scheme 2). Compounds $\mathbf{3}$ and $\mathbf{6}$ turned to be stable, and were therefore isolated with respectively 41 and $46 \%$ yield (two-step overall yield from 1). The yields are relatively good considering that they correspond to seven reactions: three nitro reductions, one hexaphyrin core reduction and three amino acylations. The straightforward formation of $\mathbf{3}$ and $\mathbf{6}$ validates our post-modification strategy, making 2 an interesting platform for the introduction of various functionalities.

As a first "naked eyes" diagnosis, hexaphyrins $\mathbf{3}$ and $\mathbf{6}$ display a deep blue color characteristic of $28 \pi$ aromatic hexaphyrins with a singly-twisted Möbius topology. The 28 electron form was confirmed by HRMS analysis, while the aromatic character was deduced from UV-vis absorption spectra, showing intense and well defined Soret-like bands at $604 \mathrm{~nm}$ for $\mathbf{3}$ and $\mathbf{6}$, as well as Q-like bands up to $1036 \mathrm{~nm}$ (Figure 3 and SI). This contrasts with the broad absorption in the visible region exhibited by Hückel antiaromatic [28] hexaphyrins. ${ }^{6,21}$

Next, the tris-acryloyl derivative 3 was reacted with tris(2aminoethyl)amine (tren) or tris[2-(methylamino)ethyl]amine (Me-tren) in a chloroform/methanol mixture. To our delight, in both cases, mass spectrometry analysis monitoring revealed the formation of the desired tren-capped compounds $\mathbf{4}$ or $\mathbf{5}$ as major products. Similarly, the tris-benzyl chloride derivative $\mathbf{6}$ was reacted with tren or Me-tren in THF in the presence of sodium iodide and diisopropylethylamine (DIPEA). Here also, formation of the targeted tren-capped compounds $\mathbf{7}$ or $\mathbf{8}$ was attested by mass spectrometry analysis. Compounds 4, 5 and $\mathbf{8}$ were isolated with moderate to good yields, respectively $41 \%$,

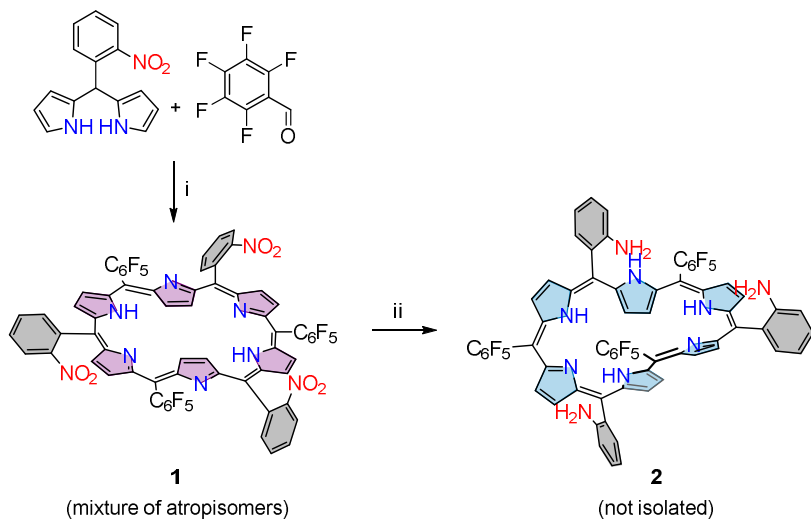

Scheme 1. Synthesis of hexaphyrin 2. Conditions: i) MSA, $\mathrm{CH}_{2} \mathrm{Cl}_{2},{ }^{\circ} \mathrm{C}$ then DDQ, $16 \%$; ii) $\mathrm{H}_{2} 80$ bars, $\mathrm{Pd}(0) / \mathrm{C}$ (cat.), AcOEt, $30^{\circ} \mathrm{C}$. 
Figure 2. X-ray crystal structure of one atropisomer of $\mathbf{1}$ (stick view, hydrogen atoms and solvents of crystallization have been removed for clarity).

$67 \%$ and $55 \%$, whereas compound 7 could not be purified due to a lack of stability. It is worth to stress the straightforward access to these capped hexaphyrins obtained in only three steps from a 5-(aryl)dipyrromethane.

In contrast to their Möbius aromatic precursors $\mathbf{3}$ and $\mathbf{6}$, the three capped hexaphyrins 4, 5 and 8 exhibit typical features of Hückel antiaromatic [28] hexaphyrins within a rectangular topology. Indeed, while HRMS analysis confirmed $28 \pi$ electron species, UV-vis spectroscopy revealed highly broaden bands between 400 to $650 \mathrm{~nm}$ (Figure 3 and SI) and Q-like bands were not observed at higher wavelength. These spectral patterns are shared by antiaromatic expanded porphyrins. ${ }^{21}$ To these spectral features corresponds a red-brownish color of the samples, strongly contrasting with the blue color of the Möbius aromatic [28] hexaphyrins. The ${ }^{1} \mathrm{H}$ NMR spectra of 4 (SI), 5 and 8 (Figure 4a and $4 \mathrm{~b}$ ) display two sets of $\beta$-pyrrolic protons pointing out a rectangular shape with two central inverted pyrroles: four protons are strongly downfield shifted (two broad signals in the 19-21 ppm region) and eight protons are upfield

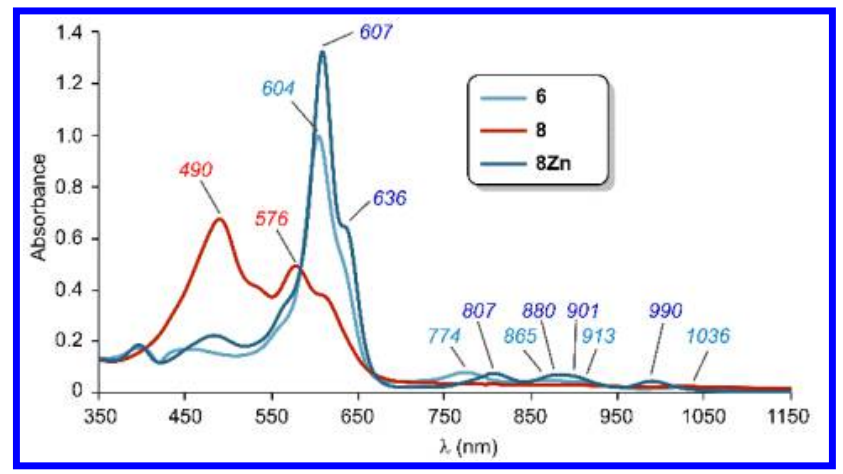

Figure 3. UV-vis-NIR absorption spectra of $\mathbf{6}\left(\mathrm{CH}_{2} \mathrm{Cl}_{2}\right), \mathbf{8}$ and

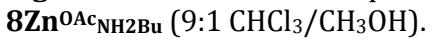

shifted (four doublets in the 3-4 ppm region). Similarly, two sets of hexaphyrin NH protons are observed, around 26-27 ppm and $2.80 \mathrm{ppm}$. These data evidence: (i) a plane of symmetry in the structures, perpendicular to the mean plane of the hexaphyrin and crossing the meso-aryl positions on the short sides. This is confirmed by the ${ }^{19} \mathrm{~F}$ NMR spectra, showing two sets of signals in 2:1 ratio corresponding to the long ("L") and short ("S") sides meso- $\mathrm{C}_{6} \mathrm{~F}_{5}$ moieties (SI); (ii) a strong paratropic ring current shielding the outside and deshielding the inside of the hexaphyrin. ${ }^{6}$ As shown in Figure $4 \mathrm{a}$, the ring current effect is strongly experienced by the tren cap of 5, with $\mathrm{NCH}_{2}$ protons reaching $8.5 \mathrm{ppm}$. The tren methyl groups are also deshielded, with a higher effect for the long side connected ones $\left(\delta_{\mathrm{NM} e(L)}=4.97 \mathrm{ppm} v s\right.$. $\delta_{\mathrm{NMe}(S)}=$ $3.73 \mathrm{ppm}$ ). In the case of $\mathbf{8}$, a similar ring current effect is observed for the tren cap unit, but to a lower extent $\left(\delta_{\mathrm{NCH} 2 \mathrm{CH} 2}\right.$ $\left.=[4.1-3.7] \mathrm{ppm}, \delta_{\mathrm{NMe}(L)}=3.47 \mathrm{ppm}, \delta_{\mathrm{NMe}(S)}=3.03 \mathrm{ppm}\right)$. This indicates a higher position of the tren cap relative to the hexaphyrin in line with longer and more rigid linkers. These data traduce a general tendency of triply bridged
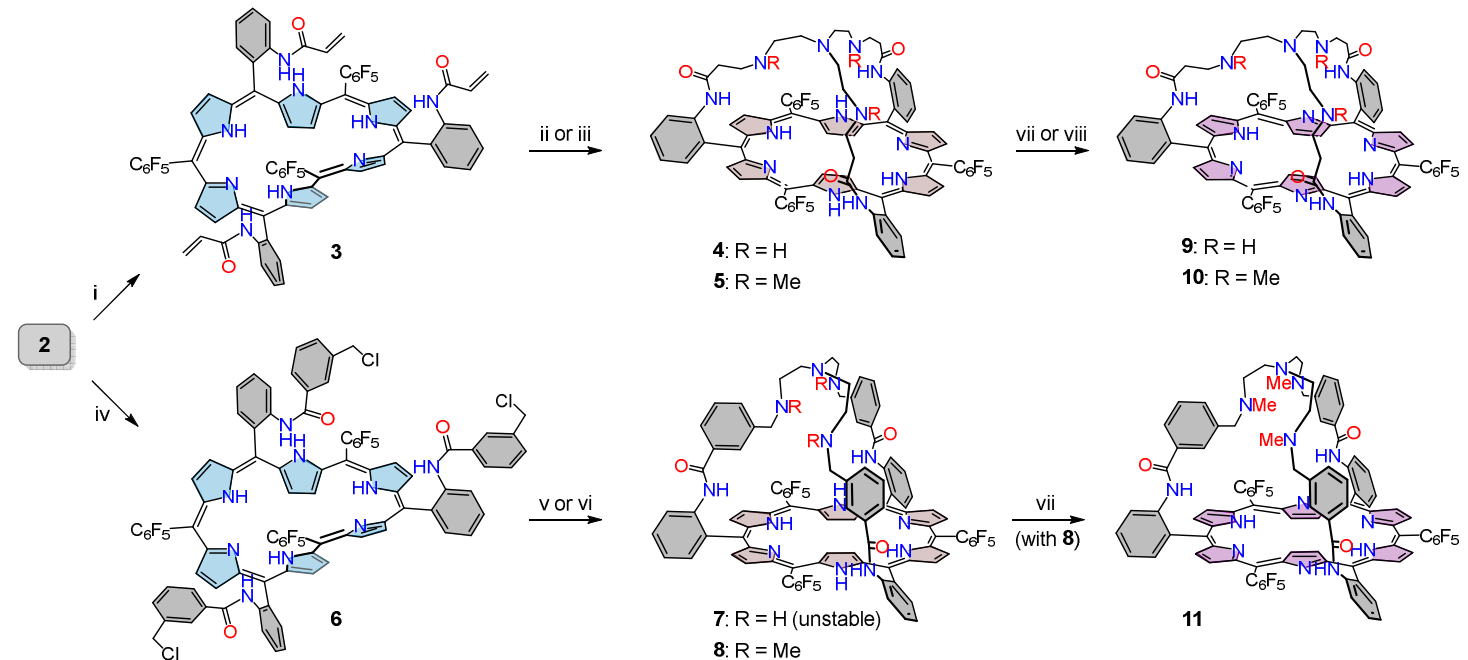

Scheme 2. Synthesis of tren-capped [28] hexaphyrins 4, 5, 7, and 8, and oxidation of compounds $\mathbf{4}, \mathbf{5}$ and $\mathbf{8}$ in their $26 \pi$ aromatic counterparts $\mathbf{9 , 1 0}$ and 11. Conditions: i) acryloyl chloride, DIPEA, THF, $-50{ }^{\circ} \mathrm{C}, 41 \%$ ( 2 steps); ii) tren, $\mathrm{CHCl}_{3} / \mathrm{CH}_{3} \mathrm{OH} 1: 9,45^{\circ} \mathrm{C}, 41$ $\%$ (4); iii) Me-tren, $\mathrm{CHCl}_{3} / \mathrm{CH}_{3} \mathrm{OH} 1: 9,45^{\circ} \mathrm{C}, 67 \%$ (5); iv) 3-(chloromethyl)benzoyl chloride, $\mathrm{Et}_{3} \mathrm{~N}, \mathrm{THF}, 0{ }^{\circ} \mathrm{C}, 46 \%$ (2 steps); v) $\mathrm{NaI}$, DIPEA, THF, $70^{\circ} \mathrm{C}$ then tren, not characterized (7); vi) NaI, DIPEA, THF, reflux then Me-tren, $50{ }^{\circ} \mathrm{C}, 55 \%(8)$; vii) $\mathrm{DDQ}, \mathrm{CDCl}_{3} / \mathrm{CD}_{3} \mathrm{OD}$ 9:1 or $\mathrm{CDCl}_{3}$ (9 and 11); (viii) DDQ $\mathrm{CHCl}_{3}, 82 \%(\mathbf{1 0})$. 

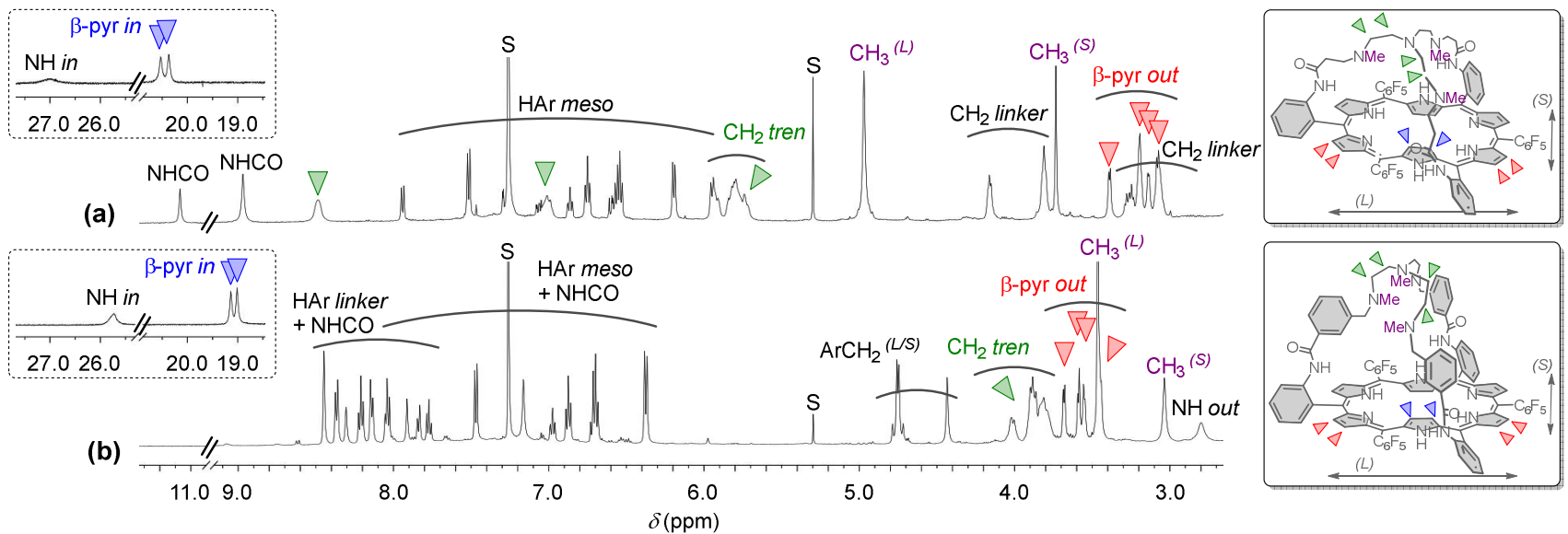

Figure 4. ${ }^{1} \mathrm{H}$ NMR spectra (selected parts) of 5 (a) and 8 (b) $\left(\mathrm{CDCl}_{3}, 298 \mathrm{~K}, 500 \mathrm{MHz}\right)$. S = solvent; "L" /"S" italicized stand for "long" /"short".

[28] hexaphyrins to adopt a rectangular antiaromatic topology, as also observed with cyclodextrin-hexaphyrin hybrids (Figure $1 \mathrm{~b}$ ). ${ }^{6}$

The crystal structure of $\mathbf{5}$ (Figure 5) confirmed the rectangular conformation of the hexaphyrin, which is slightly curved (concave side oriented towards the cap, Figure 5b) and distorted on one of the large side. This is possibly due to some strain in the structure because of the small size of the cap. Indeed, the Me-tren unit adopts an extended dissymmetric conformation and lies at a rather short distance of $\sim 3.5 \AA$ from the hexaphyrin core. ${ }^{22}$ This conformation is stabilized by intramolecular H-bonds between the three NMe atoms of the cap (N10, N11, N12) and the NHCO of the meso-aryl units (N7, N8, N9; dashed lines and distances in Figure $5 b$ and $c)$. The strong ring current effect experienced by the Me-tren cap in NMR solution is consistent with this conformation.

Exploring their aromaticity switching capability, the three capped [28] hexaphyrins 4, 5 and $\mathbf{8}$ were oxidized with DDQ in their $26 \pi$ forms, as confirmed by HRMS analysis, giving respectively compounds $\mathbf{9 , 1 0}$ and $\mathbf{1 1}$ (Scheme 2). These [26] hexaphyrins exhibit deep purple coloration, and the UV-vis-NIR absorption spectrum of 10 shows intense Soretlike band at $570 \mathrm{~nm}$ with Q-like bands at 718, 904 and 1028 $\mathrm{nm}$ (SI), which is characteristic of aromatic [26]hexaphyrins. In addition, ${ }^{1} \mathrm{H}$ and ${ }^{19} \mathrm{~F}$ NMR spectra of $\mathbf{9 , 1 0}$ and 11 agree with rectangular conformations with two inverted central pyrroles, and exhibiting a diatropic ring current. Indeed, shielding effects are opposite to those observed for the parent $28 \pi$ compounds (SI).

Our first investigations of the coordination properties of these tren-capped hexaphyrins led to unexpected results, as shown hereafter with zinc. The Zn(II) complexation of 8 was investigated by ${ }^{1} \mathrm{H}$ NMR and UV-vis absorption spectroscopies in $\mathrm{CDCl}_{3} / \mathrm{CD}_{3} \mathrm{OD}$ 9:1 solution. Whereas our initial attempts with only $\mathrm{Zn}(\mathrm{OAc})_{2}$ or $\mathrm{Zn}(\mathrm{OTf})_{2}$ remained unsuccessful, we found that a zinc metal complex of $\mathbf{8}$, namely
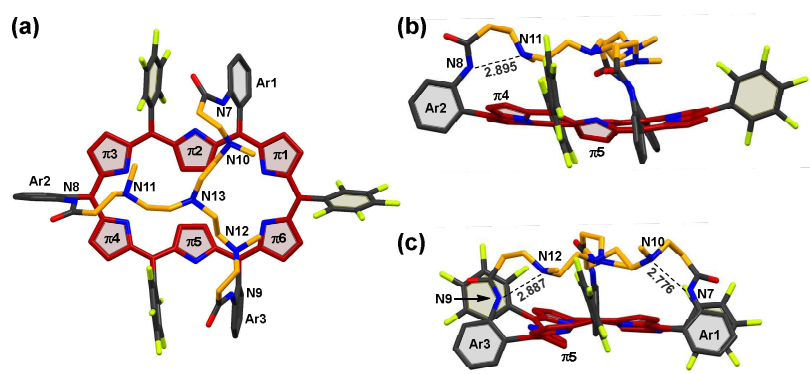

Figure 5. X-ray crystal structure of 5: (a) top view; (b) and (c): side views from respectively the long side and the short open side (stick representation, hydrogen atoms have been removed for clarity). Brown: hexaphyrin part; orange: Me-tren- $\mathrm{CH}_{2} \mathrm{CH}_{2}$ unit. Dashed lines: H-bonds with distances in $\AA$.

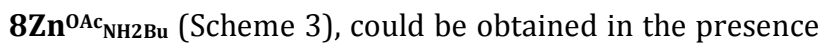
of both acetate ions and a primary amine. For instance, according to pathway A, addition of 1 equiv. of $\mathrm{Zn}(\mathrm{OTf})_{2}$ to 8 led to an ill-defined NMR spectrum, even at low temperatures (down to $223 \mathrm{~K}$ ), with notably disappearance of the signal of the inner $\beta$-pyrrolic protons at $17.1 \mathrm{ppm}$ (Figure $6 \mathrm{~b}$ ). Subsequent addition of either 1 equiv. of TBAOAc (Figure $6 \mathrm{c}$ ) or 1 equiv. of $\mathrm{BuNH}_{2}$ (Figure $6 \mathrm{~d}$ ) led only to minor changes. Conversely, addition of both TBAOAc and $\mathrm{BuNH}_{2}$ (1 equiv. each) led to a sharp NMR pattern suitable for 2D NMR analysis (Figure 6e), along with a blue color of the solution contrasting with the red-brownish one of the starting antiaromatic compound. The corresponding UV-vis absorption spectrum is characterized by an intense Soret-like band at $607 \mathrm{~nm}$ as well as Q-like bands at 807, 880, 901 and 990 $\mathrm{nm}$, suggesting the formation of an aromatic species (Figure 3 and SI). ${ }^{23}$ The $\beta$-pyrrolic protons distribution fits with a twisted Möbius topology exhibiting diatropic ring current (Scheme 3): ${ }^{2 \mathrm{~b}}$ eight doublets in the 8.5-7.0 ppm region (four out pyrroles: $\pi 1, \pi 3, \pi 4, \pi 6$ ), two doublets at 4.59 and 4.37 ppm (twisted pyrrole: $\pi 5$ ) and two other doublets in the highfields, at -1.72 and $-3.50 \mathrm{ppm}$ (inverted pyrrole: $\pi 2$ ). A sharp singlet at $-2.21 \mathrm{ppm}$, integrating for three protons, 
corresponds to a single acetato ligand (evidenced by ROESY, HSQC, and HMBC 2D NMR), bound to the Zn(II) center (vide infra) and located in the shielding region of the hexaphyrin. This defines an endo coordination mode. A butylamino ligand is also bound to the $\mathrm{Zn}$ (II) center in an exo fashion (vide infra), as evidenced by 2D ROESY experiment. ${ }^{24}$ The $\alpha$ and $\beta \mathrm{CH}_{2}$ protons of $\mathrm{BuNH}_{2}$ become diastereotopic in the complex, which arises from the inherent chirality of the Möbius band. An aromatic moiety of a linker (Ar6) experiences a strong shielding environment, with the ortho, meta, and para protons relative to the carbonyl located at 1.28, 3.07 and $3.41 \mathrm{ppm}$ (Scheme 3, pathway A). Also, a NOE correlation is observed between the ortho aromatic proton at 1.28 $\mathrm{ppm}$ and the endo-acetato ligand at $-2.21 \mathrm{ppm}(\mathrm{SI})$. This evidences a deep conformational change of the tren unit upon hexaphyrin metallation, projecting Ar6 above the Möbius aromatic ring, in close proximity to the endo-acetato ligand. As revealed by an X-ray diffraction structure (see below), the tren cap is mono-protonated in these conditions (Scheme 3, pathway A: $\mathbf{8 Z n}^{\text {OAc }}{ }_{\mathrm{NH} 2 \mathrm{Bu}} \mathbf{H}^{+}, \mathbf{O T f}$ ), i.e. in the absence of a base in the medium. ${ }^{25}$ Interestingly, whether the metallation is performed with $\mathrm{Zn}(\mathrm{OAc})_{2}, \mathrm{BuNH}_{2}$ and an excess of DIPEA (Scheme 3, pathway B), or DIPEA was added subsequently to pathway A, a similar neutral Zn(II) Möbius

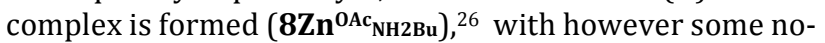
ticeable chemical shift differences (Figure $6 \mathrm{f}$ and SI): (i) a more important shielding of the twisted ( $\pi 5$ ) and inverted

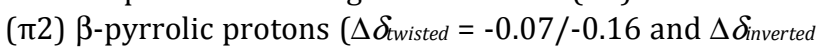
$=-0.40 /-0.28 \mathrm{ppm} ; \Delta \delta=\delta$ «protonated» $-\delta$ «neutral»), (ii) a less important shielding of the acetato ligand $(\Delta \delta=0.16$ $\mathrm{ppm}$ ) and of the inward oriented $\operatorname{Ar} 6$ moiety ( $\delta$ values in Scheme 3, pathway B). The latter observation indicates a different conformation of the neutral tren cap, which is likely less constrained. Hence, the mono-protonation of the

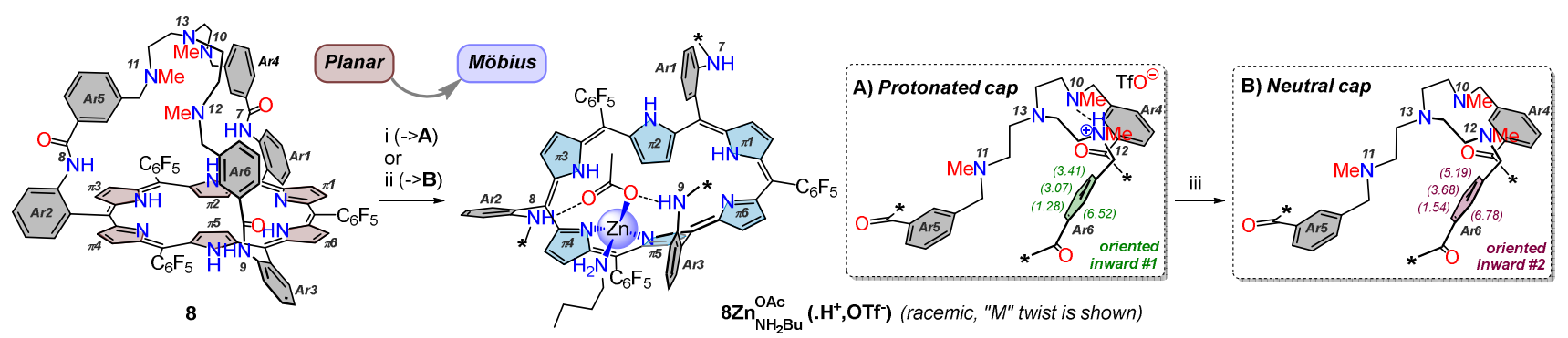

Scheme 3. Planar-to-Möbius topological change observed during $\mathrm{Zn}(\mathrm{II})$ metallation of $\mathbf{8}$. Conditions ( $\left.\mathrm{CDCl}_{3} / \mathrm{CD}_{3} \mathrm{OD} 9: 1,298 \mathrm{~K}\right):$ i) 1 equiv. $\mathrm{Zn}(\mathrm{OTf})_{2}, 1$ equiv. TBAOAc, 1 equiv. $\mathrm{BuNH}_{2}$; ii) 3.5 equiv. $\mathrm{Zn}(\mathrm{OAc})_{2}, 7$ equiv. DIPEA, 3 equiv. BuNH${ }_{2}$; iii) 10 equiv. DIPEA. Inset: chemical shift values (in parentheses) of the inward oriented aromatic moieties of a linker (Ar6).

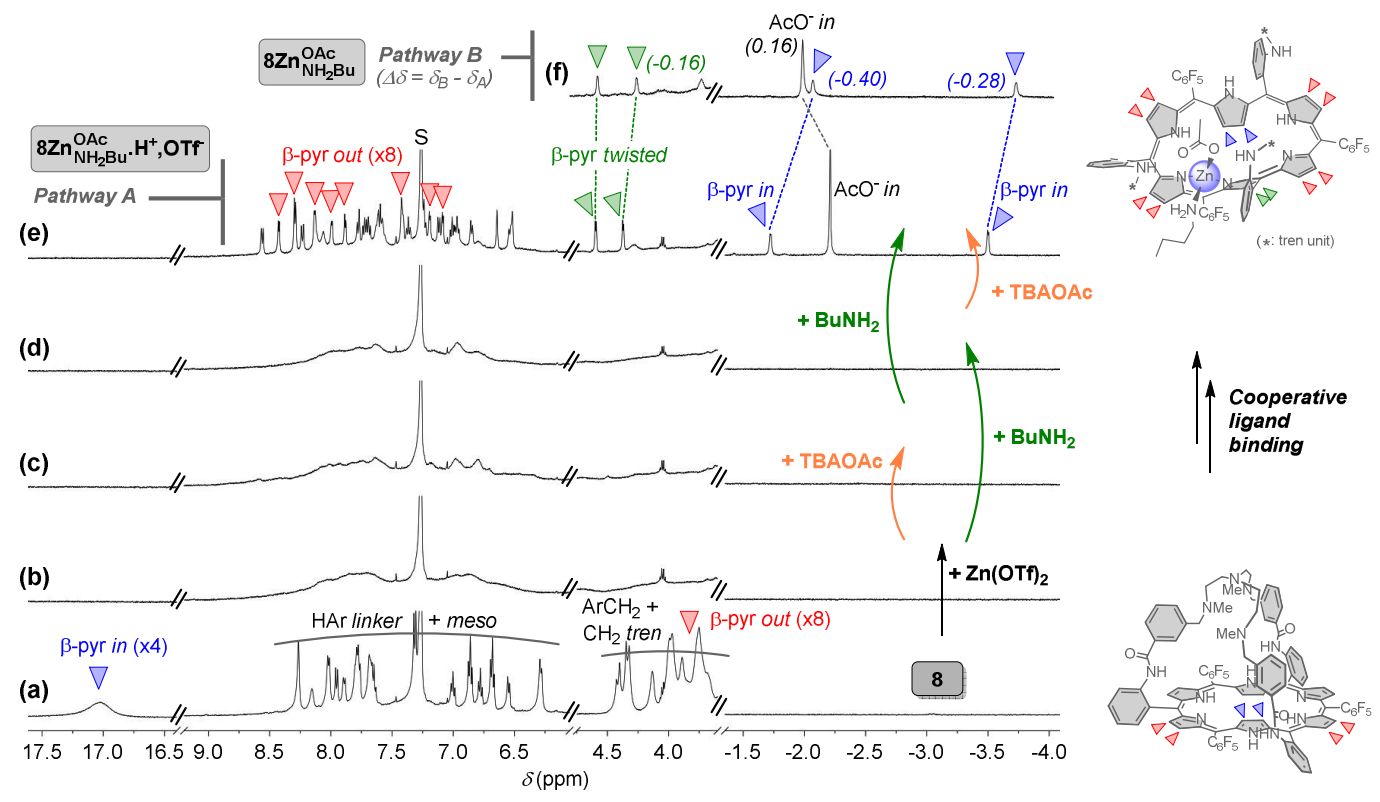

Figure 6. ${ }^{1} \mathrm{H}$ NMR study of the metallation of 8 with $\mathrm{Zn}$ (II) in two sets of conditions, namely pathway A (a-e) and pathway B (f) $\left(\mathrm{CDCl}_{3} / \mathrm{CD}_{3} \mathrm{OD} \text { 9:1, } 298 \mathrm{~K}, 500 \mathrm{MHz} \text {, selected regions). Conditions, pathway A: (a) 8, (b) } 8+1 \text { equiv. Zn(OTf }\right)_{2}$, (c) $8+1$ equiv. Zn(OTf) +1 equiv. TBAOAc, (d) $8+1$ equiv. $\mathrm{Zn}(\mathrm{OTf})_{2}+1$ equiv. $\mathrm{BuNH}_{2}$, (e) $8+1$ equiv. $\mathrm{Zn}(\mathrm{OTf})_{2}+1$ equiv. TBAOAc +1 equiv. $\mathrm{BuNH}_{2} ;$ pathway B: (f) $8+3.5$ equiv. $\mathrm{Zn}(\mathrm{OAc})_{2}+7$ equiv. DIPEA +3 equiv. $\mathrm{BuNH} 2 . \mathrm{S}=$ solvent. 
(a)

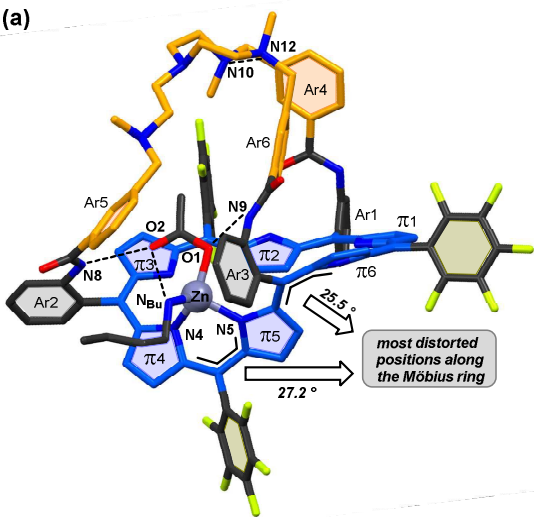

(b)

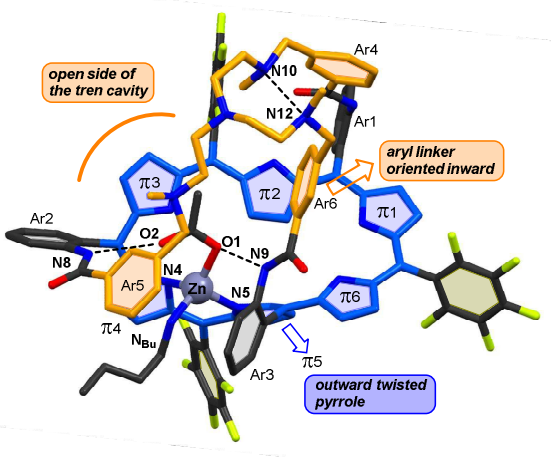

(c)

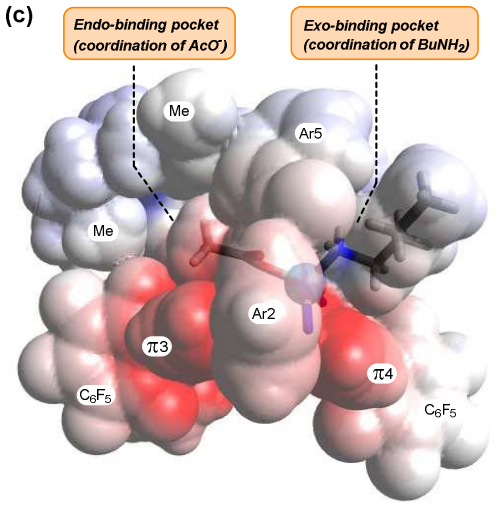

Figure 7. X-ray crystal structure of $\mathbf{8 Z n}^{\mathbf{O A c}} \mathrm{NH}_{\mathrm{N} 2 \mathrm{Bu}} \cdot \mathrm{H}^{+}, \mathbf{O T f}$ : (a) side and (b) top views (stick representation, hydrogen atoms, triflate counterion and solvents of crystallization have been removed for clarity; dashed lines indicate H-bonds). Blue: hexaphyrin part; orange: Me-tren- $\mathrm{CH}_{2} \mathrm{Ar}$ unit. (c): perspective view from Ar2, highlighting the buried coordination site of $\mathrm{Zn}$ (II) affording endo- and exo-binding pockets (Van der Waals surface colored by electrostatic potential: blue/red for positive/negative potential; stick representation for the acetato and butylamino ligands, sphere representation for zinc). Selected distances ( $\mathrm{A})$ : N5-Zn 1.990, N4-Zn 2.044, $\mathrm{N}_{\mathrm{Bu}}$-Zn 2.049, 01-Zn 1.997, 01-N9 2.836, 02-N8 2.878, 02-N $\mathrm{N}_{\mathrm{Bu}}$ 3.062, N10-N12 2.949. Selected angles ( $\left.{ }^{\circ}\right)$ : 01-Zn-N5 103.07, 01-ZnN4 120.34, 01-Zn-N $\mathrm{Bu}_{\mathrm{Bu}} 115.87, \mathrm{~N} 5-\mathrm{Zn}-\mathrm{N} 4$ 95.17, N5-Zn-N $\mathrm{N}_{\mathrm{Bu}}$ 115.42, N4-Zn-N $\mathrm{N}_{\mathrm{Bu}}$ 105.51. Dihedral angles along the SMC: see the SI.

tren cap induces a cascade of conformational changes involving the distortion of the tren cap itself, the inward orientation of a linker, the molecular twist of the hexaphyrin, and in turn the fit between the endo acetato ligand and the confined space provided by the tren-hexaphyrin environ-

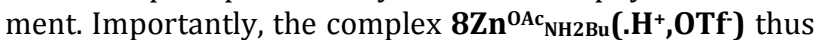
corresponds to a heteroditopic receptor featuring allosteric communication between its two distinct recognition sites, i.e. the tren unit (allosteric site) and the Zn-dipyrin unit (two-ligand binding site). ${ }^{27,28}$

Considering these findings, several remarkable features have to be highlighted:

(i) ligand $\mathbf{8}$ shows a total selectivity of metallation for the hexaphyrin $v s$. the tren binding site;

(ii) the metallation process at a dipyrrin site is instantaneous at room temperature, suggesting an assistance mechanism of the tren unit;

(iii) in contrast to all Möbius hexaphyrin metal complexes reported to date, the herein described Möbius complex does not involve $\beta$ - $\mathrm{CH}$ activation of the inverted central pyrrole but features a NNNO coordination sphere (vide infra);

(iv) the cooperative binding of two exogeneous ligands (amino and acetato), that triggers conformational restriction of a Möbius hexaphyrin metal complex, is unprecedented. ${ }^{29}$ The planar-to- singly-twisted topological change allows antiaromatic-to-aromatic transformation;

(v) the tren cap provides a basic site that can be selectively protonated without hexaphyrin demetallation. This makes possible an allosteric communication between the tren and hexaphyrin units.

The crystal structure obtained from an NMR tube solution (pathway A) revealed the five component assembly

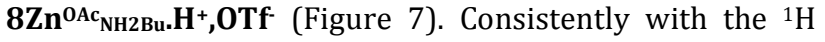
NMR data, the hexaphyrin is twisted in a Möbius topology. One of the two inverted pyrroles of $\mathbf{8}$ remains in its initial position $(\pi 2)$, whereas the other one $(\pi 5)$ is "twisted outward", opposite to the tren cap (Figure 7b). The meso positions adjacent to $\pi 5$ correspond to the most distorted ones along the Möbius ring with dihedral angles of $25.5^{\circ}$ and $27.2^{\circ}$ (Figure $7 \mathrm{a}$ ). This topology projects (i) the meso-aryl group Ar3 towards the tren cap and (ii) the linker aryl group Ar6 towards the hexaphyrin ring (Figure 7b), which explains the important ${ }^{1} \mathrm{H}$ NMR upfield shifts of these aromatic protons (Scheme 3, inset). The zinc(II) cation is bound to a dipyrrin unit (N4 and N5), to an acetato (01) and to a molecule of butylamine $\left(\mathrm{N}_{\mathrm{Bu}}\right)$, in a tetrahedral environment (selected distances and angles in caption of Figure 7). The metal center is surrounded by two aromatic groups, one from a linker (Ar5) and one at the most distorted meso position (Ar3). The coordinated butylamine is also surrounded by these two aromatic groups with its alkyl chain oriented outwards, defining an exo coordination mode (Figure 7c). Conversely, the acetato ligand lies almost above $\pi 3$ of the hexaphyrin macrocycle, and is somehow buried inside a distorted cavity formed by the pinched Me-tren unit and its aromatic linkers, defining an endo coordination (Figure $7 \mathrm{c}$ ). This positioning is consistent with the ${ }^{1} \mathrm{H}$ NMR chemical shift of -2.21 ppm of the acetato methyl group (Figure 6e). Reminiscently to the "funnel access" of the buried active site of enzymes, the tren cavity features an open space delineated by one tren arm, $\pi 3$, Ar2, and a meso $\mathrm{C}_{6} \mathrm{~F}_{5}$ moiety, affording an access to the metal center and allowing acetate exchange with the medium (Figure 7c). The resulting exo/endo selectivity of coordination is ascribed to a second sphere of coordination possible only with an endo bound acetato. The acetato is indeed stabilized by two hydrogen bonds with the amide groups of the linkers (dashed 
lines between 01-N9 [2.836 $̊$ and 02-N8 [2.878 Å], Figure $7 \mathrm{a}, \mathrm{b})$. An additional one is found between 02 of the acetato and the $\mathrm{NH}_{2}$ of the butylamine (O2- $\mathrm{N}_{\mathrm{Bu}}[3.062 \AA]$ ). As mentioned above, the tren unit is rather distorted and protonated at N12 position, the triflate counterion being dissociated and stabilized by multiple weak intermolecular interactions with e.g. $\mathrm{C}_{6} \mathrm{~F}_{5}$ groups. This conformation is likely stabilized by hydrogen bonding interactions between the two NMe atoms N10 and N12, held in close proximity (N10-N12 [2.949 ̊], dashed line in Figure 7b).

Conformational analysis of the molecular twist of

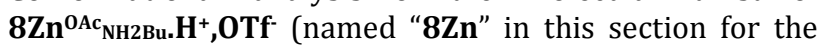
sake of conciseness) has been performed and compared with other Möbius hexaphyrins, based on available experimental data (molecular structures and ${ }^{1} \mathrm{H}$ NMR spectra). Indeed, considering the close relationship between ring
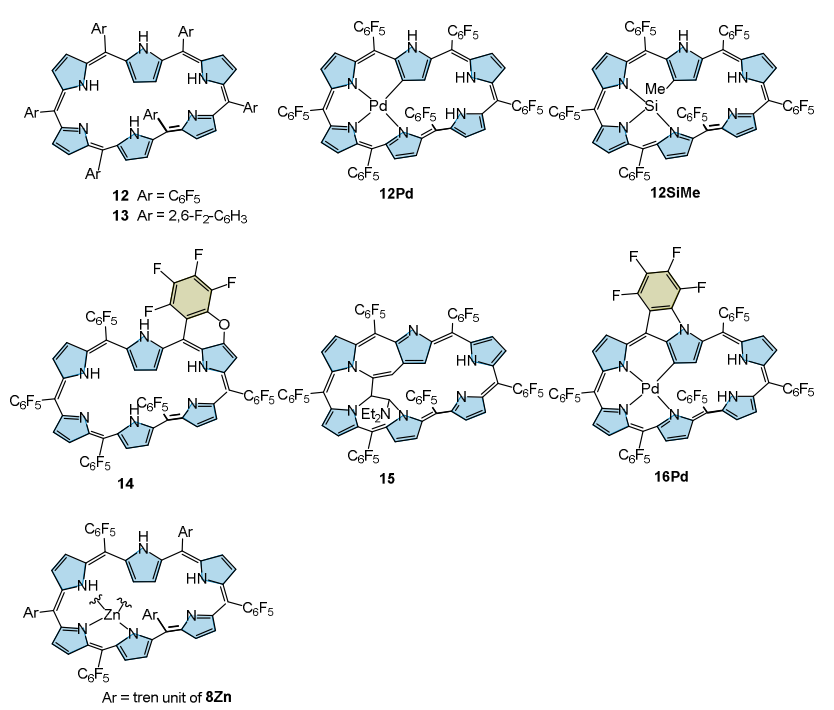

Chart 1. Selected Möbius aromatic hexaphyrins.

Table 1. Comparison of geometric and magnetic parameters of Möbius twisted hexaphyrins.

\begin{tabular}{lllll}
\hline Entry & Compound & $\varphi^{\mathrm{a}}$ & $\Pi^{\mathrm{b}}$ & $\Delta \delta^{\mathrm{c}}$ \\
\hline 1 & $\mathbf{1 2}^{2 \mathrm{~b}}$ & $26.5^{\mathrm{d}}$ & - & $10.21^{\mathrm{e}}$ \\
2 & $\mathbf{1 3}^{2 \mathrm{~b}}$ & 26.5 & -0.538 & - \\
3 & $\mathbf{1 2 P d}^{32}$ & 38.2 & -0.382 & 7.05 \\
4 & $\mathbf{1 2 S i M e}^{33}$ & 40.7 & -0.411 & 6.98 \\
5 & $\mathbf{1 4}^{35}$ & 44.9 & -0.441 & 6.41 \\
6 & $\mathbf{1 5}^{36}$ & 31.7 & -0.476 & 10.20 \\
7 & $\mathbf{1 6 P d}^{34}$ & 40.5 & -0.355 & 7.73 \\
8 & $\mathbf{8 Z n}^{3}$ & 27.2 & -0.523 & 11.93 \\
\hline
\end{tabular}

a Largest dihedral angle belonging to the SMC $\left(\left[^{\circ}\right]\right.$, absolute values). $b$ Torsional $\pi$-conjugation index calculated for the SMC. $c$ Difference (ppm) between the most upfield and downfield

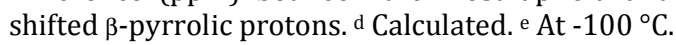

strain, $\pi$-orbital overlapping and aromaticity, it is important to evaluate the ring strain of the molecular twist according to different strategies used to lock the conformation. Indeed, the native Möbius hexaphyrin skeleton is flexible and exhibits fluxional equilibrium between degenerate conformers. $^{2 b}$ For that, we have compared for a set of representative Möbius twisted [28] hexaphyrins (Chart 1), (i) the largest dihedral angles ( $\varphi$, absolute value) as well as (ii) the torsional $\pi$-conjugation index $(\Pi)^{30}$ along the smallest macrocyclic circuit (SMC), and (iii) the chemical shift difference $(\Delta \delta)$ between the most upfield and downfield shifted $\beta$-pyrrolic protons (Table 1). ${ }^{31}$ The selected hexaphyrins differ by their levels of strain, that rely either on a molecular twist (for all), coordination of a metal ion (for 12Pd, ${ }^{32}$ 12SiMe, ${ }^{33}$ ${ }_{16 d^{34}}$ and 8Zn), fused rings/internal bridges (for 14, ${ }^{35}$ $15^{36}$ and $16 \mathrm{Pd}$ ) or a capping of the meso positions (for $\mathbf{8 Z n}$ only). Stępień and Latos-Grażyński proposed the torsional $\pi$-conjugation index as a rough estimation of the efficiency of the $\pi$-conjugation. The $\Pi$ value is close to 0 for macrocycles with torsion of $c a . \sim 90^{\circ}$, and approaches -1 for infinite Möbius rings with uniformly distributed torsion. Combined to the chemical shift difference $\Delta \delta$, these parameters allow qualitative ${ }^{37}$ assessment of the $\pi$-conjugation efficiency. In the present tren-capped Zn complex, the strain induced by the ring twist is dissipated along the conjugated chain, similarly to the more flexible hexaphyrins $\mathbf{1 2}$ and $\mathbf{1 3}^{\mathrm{2b}}$ with a largest dihedral angle of $27^{\circ}$ (entry 8 vs. 1,2). Conversely, the more rigid metallated hexaphyrins 12Pd and 12SiMe display more localized distorted positions $\left(\varphi \approx 40^{\circ}\right.$, entries 3,4 ) due to respectively the Pd enforced planar coordination environment and to the Si trigonal bipyramidal coordination at the NNNC coordination site. A more localized distortion is also observed in the fused system $14\left(\varphi \approx 45^{\circ}\right.$, entry 5). Thus, as compared to these NNNC metallated and fused hexaphyrins, $\mathrm{Zn}$ coordination at a dipyrrin site of the capped hexaphyrin 8 should preserve substantial $\pi$-conjugation. Indeed, the $\Pi$ values closest to -1 are obtained for the free base $\mathbf{1 3}$ and for $\mathbf{8 Z n}$ (entries 2,8) whereas the closest to 0 are found for the palladium complexes 12Pd and 16Pd (entries 3,7 ), fused/bridged compounds having intermediate $\Pi$ values (entries 5-7). These tendencies are well reflected by the magnetic shielding experienced by the $\beta$-pyrrolic protons. 8Zn displays the highest $\Delta \delta(11.93 \mathrm{ppm})$, followed by the free base $\mathbf{1 2}(10.20 \mathrm{ppm})$ and, surprisingly, by the bridged compound $\mathbf{1 5}$ (entries 8, 1 and 6). Much lower $\Delta \delta$ are found for all other Möbius hexaphyrins (below 8 $\mathrm{ppm}$, Table 1). This conformational analysis stresses that a fine balance has to be found when using coordination and/or covalent chemistry to lock the hexaphyrin macrocycle in a Möbius conformation. Notably, the strength afforded by NNNC-type coordinations is paid by a less uniform distribution of the twist, hence the less efficient $\pi$-conjugation. $\mathrm{Zn}$ coordination at a dipyrrin site combined to the capping of the meso positions in $\mathbf{8 Z n}$ affords a more labile complex (vide infra) but does not perturb so much the $\pi$-conjugation. The smooth metallation conditions of $\mathbf{8}$ arising from cooperative exogeneous ligand binding appeared to us interesting in view of sensing systems featuring a chiroptical out- 
put: (i) on the one hand, antiaromatic-to-aromatic transformation has a profound impact on the electronic properties of the heteroannulene; (ii) on the other hand, Möbius hexaphyrins are inherently chiral and characterized by important optical rotatory strengths. ${ }^{38}$ Therefore, the use of an optically active ligand, triggering stereoselective Möbius strip formation when binding to Zn(II), may allow a chiroptical sensing. More precisely, the use of a chiral acetato (/amino) should allow chiroptical detection of its "complementary" amino (/carboxylato) containing compounds thanks to cooperative binding.

To test this idea, we have investigated the $\mathrm{Zn}(\mathrm{II})$ metallation process of $\mathbf{8}$ in the presence of various chiral acetato and amino ligands (Table 2, SI): on the one hand, different carboxylate derivatives in conjunction with $\mathrm{BuNH}_{2}$ and on the other hand, various amines in conjunction with acetate. Although deeper studies would be needed to select ligands that best fit with this environment, it appears that steric discrimination is more severe for the endo- vs. exo-coordination to the zinc center. Indeed, whereas a Möbius complex was mainly obtained with the propionato ligand, the presence of a tertiary carbon in $\alpha$ position relative to the carbonyl allowed only partial formation of well-defined Möbius complexes (entries 2 vs. 3-5). Although the propionato experiences the chirality of the Möbius ring $\left(\alpha-\mathrm{CH}_{2}\right.$ protons are diastereotopic), no chiral induction was observed in the case of $(S)$-2-methylbutyric acid (entry 3). Comparison of the $\Delta \delta$ for the $\beta$-position relative to the carbonyl $(-2.21$ to -3.88 $\mathrm{ppm}$ ) leads to the conclusion that the carboxylato ligands

Table 2. Various ligands and conditions used for the formation of a Möbius Zn(II) complexes of 8.

$\begin{array}{ll}\text { Entry } & \text { d.e. (temp.) })^{\mathrm{b}} \text { or remark } \\ \text { Diastereotopic protons }(330 \mathrm{~K})^{\mathrm{c}}\end{array}$

a $\Delta \delta=\delta_{\text {bound }}-\delta_{\text {iree; }}$ b Estimated error $= \pm 5 \%$; c Pathway B; d Pathway A; e Modified conditions: excess of all reactants [Zn(OTf), DIPEA, $\mathrm{RCOOH}, \mathrm{R}^{\prime} \mathrm{NH}_{2}$ ]; ${ }^{\mathrm{f}}$ The d.e. could not be determined. 
have different orientations relative to the Möbius ring, due to the confined environment provided by the tren cap.

To our delight, the use of $\alpha$-methylbenzylamine (MBA) as amino ligand revealed substantial chiral induction. Indeed, the addition of 1 equiv. of $(S)$-MBA to a solution of 8,1 equiv. of $\mathrm{Zn}(\mathrm{OTf})_{2}$ and 1 equiv. of TBAOAc (pathway A), led to the formation of two Möbius complexes in a $c a$. 85:15 ratio based on ${ }^{1} \mathrm{H}$ NMR integration (Figure 8a, Table 2 entry 6). ${ }^{39}$ For instance, two singlets at -2.21 and -2.26 ppm (minor and major acetato $)^{40}$ and two sets of inner $\beta$-pyrrolic protons (1.67/-3.44 [major] and -1.70/-3.44 [minor] ppm, Figure 8a) are observed. ${ }^{41}$

This sequence of metallation was also analyzed by circular dichroism (CD). No signal was observed either in the presence of 8, $\mathrm{Zn}(\mathrm{OTf})_{2}$ and TBAOAc, or upon addition of $\mathrm{BuNH}_{2}$ (formation of $\mathbf{8 Z n ^ { \mathbf { O A c } }} \mathbf{B u N H 2}_{2}$, Figure $8 \mathrm{~b}$ ). However, using either $(S)$ - or $(R)$-MBA as amino ligand led to intense CD responses with Cotton effects. ${ }^{42}$ The CD spectra for MBA adducts of opposite configurations are mirror images, indicating stereoselective formation of Möbius rings with opposite helicity (Figure 8a). These Möbius hexaphyrins with opposite twist arise from the outward projection of one or the other inverted pyrroles of 8 ( $\pi 2 v s$. $\pi 5$ ), leading to inward orientation of Ar4 or Ar6 of the linkers, as displayed by the green/red arrows in Figure 8a.

For $(S)$ - or $(R)$-MBA, the CD signature corresponds to the difference between the CD spectra of the major and minor diastereomers. Considering their 85:15 ratio (NMR data), the $C D$ response reflects well the CD spectra of the major twist. Besides, the CD signatures are very similar to those of optically active enantiopur Möbius hexaphyrin metal complexes, which allowed attribution of the $M$ twist as major with $(S)$-MBA based on the sign of the Cotton effect $(\boldsymbol{M}-(\boldsymbol{S})$ $\mathbf{8 Z n}^{\text {OAс }}$ мва, Figure 8a). ${ }^{38 \mathrm{a}}$ In addition, whereas chiral induction was decreased to $51 \%$ d.e. with $(S)-1-(1-n a p h-$ thyl)ethylamine, it was slightly improved to $77 \%$ d.e. using $(S)$ - $\alpha$-ethylbenzylamine (Table 2, entries 7 and 8). Remarkably, the latter d.e. value corresponds to the highest chiral induction reported so far for a Möbius hexaphyrin, ${ }^{43}$ and more generally for a Möbius compound.

Formally, this process corresponds to the chiroptical detection of an acetato ligand based on its cooperative binding to $\mathrm{Zn}$ with a chiral amino ligand. Indeed, a CD signature was obtained only upon addition of TBAOAc to a mixture of $\mathbf{8}$, $\mathrm{Zn}(\mathrm{OTf})_{2}$ and $(R)$-MBA (SI). This constitutes a proof of concept for a sensing system relying on the stereoselective formation of a Möbius hexaphyrin triggered by an analyte. As an additional encouraging preliminary result along this line, we observed by ${ }^{1} \mathrm{H}$ NMR that the OMe derivative of dopamine fits well with the Möbius architecture of "8Zn" in the presence of AcO- Such a Möbius complex, even as a minor species, could also be detected in conjunction with lactic acid (Table 2, entries 9 and 10, SI).

The energy barrier for the $M<->P$ twist inversion in "8Zn" was also evaluated through a two-step procedure, involving monitoring of the CD signal intensity upon chiral-to-achiral ligand exchange (SI). Thus, no CD signal was anymore (a)
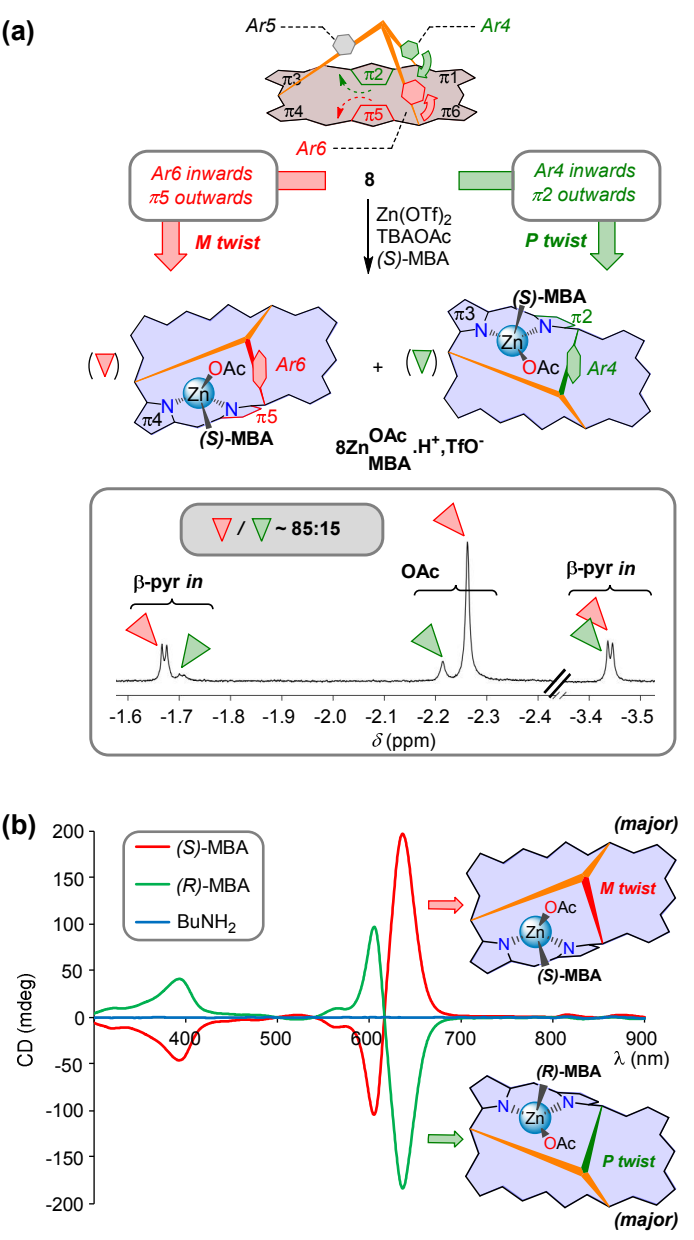

Figure 8. (a) Diastereoselective formation of Zn(II) Möbius complexes of 8 with (S)-MBA and corresponding ${ }^{1} \mathrm{H}$ NMR spectrum $\left(\mathrm{CDCl}_{3} / \mathrm{CD}_{3} \mathrm{OD}\right.$ 9:1, $276 \mathrm{~K}$, highfield region). (b) $\mathrm{CD}$ spec-

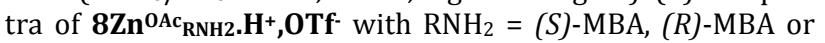
$\mathrm{BuNH}_{2}$ (red, green and blue traces, respectively; initial concentration of $8=40 \mu \mathrm{M}$ ).

detected after $10 \mathrm{~min}$ heating at $80^{\circ} \mathrm{C}$. In a qualitative manner, ${ }^{44}$ this led to the conclusion that "8Zn", deprived of metal-carbon bond, is more labile as compared to the Pd complex 12Pd with a NNNC coordination sphere, for which racemization occurred only in drastic conditions $\left(120^{\circ} \mathrm{C}\right.$, overnight). ${ }^{38 a}$

\section{CONCLUSION}

In conclusion, we have developed a straightforward access to hexaphyrins bearing a tripodal tren cap unit. Our strategy relies on the functionalization of the meso-tris(2-aminophenyl)hexaphyrin platform 2 , accessible in two steps from a dipyrromethane precursor. For both $26 \pi$ and $28 \pi$-electron species, the capping of the hexaphyrin by different tren units stabilizes the rectangular planar conformation, affording respectively Hückel aromatic and antiaromatic compounds. Coordination studies with antiaromatic tren- 
capped [28]hexaphyrin 8 have revealed a unique multifaceted ligand:

\section{(i) metallation-induced Möbius topology and aromaticity}

Zn(II) metallation occurs very smoothly and selectively at a dipyrrin site, provided a cooperative binding of both an acetato and an amino exogeneous ligand to the metal center. The metal-hexaphyrin association triggers a deep conformational change, i.e. formation of a Möbius ring, giving rise to a strong aromatic character. The tren cap does not induce noticeable ring strain, and efficient $\pi$-conjugation along the molecular twist is preserved as deduced from X-ray diffraction and ${ }^{1} \mathrm{H}$ NMR data.

\section{(ii) enzyme-like selective ligand binding - allosteric site}

The metal center is buried inside a dissymmetric confined environment including the distorted tren cap, affording endo- and exo-binding pockets. A total endo/exo selectivity of ligand-metal binding is achieved, ascribed to a second sphere of coordination between the endo acetato and two amide groups of the meso-aromatic units. In addition, this confined environment provides steric discrimination between different carboxylato ligands. These features are reminiscent to metallo-enzyme active sites, capable of encaging and discriminating small molecules by means of multiple weak interactions. Moreover, mono-protonation of the tren cap of the metal complex induces a cascade of conformational changes relayed to the hexaphyrin twist and, in turn, experienced by the acetato ligand. This constitutes a form of allosteric communication between two distinct recognition sites, i.e. the tren and Zn-dipyrrin units.

(iii) chiroptical sensing through stereoselective formation of a Möbius twist

Remarkably, substantial chiral induction of the Möbius twist up to $77 \%$ d.e. occurs with chiral amino ligands such as methyl or ethylbenzylamine, with the highest stereoselectivity reported to date for a singly twisted molecule. The asymmetric Möbius ring formation is triggered by an acetato ligand through cooperative binding to the metal center and is accompanied by an intense signature in circular dichroism. This last result is appealing in view of innovative sensing systems relying on the stereoselective formation of a Möbius twist.

Thus, molecular hosts with a Möbius geometry have been discovered for the first time, connecting Nature's ubiquitous concept of molecular recognition to Möbius aromaticity, whose Nature is deprived of. Current efforts in our group are directed towards the specific metallation of the tren unit of the herein described compounds, diversification of capped hexaphyrin ligands, and more generally the development of new Möbius-type allosteric sensors and catalysts.

\section{ASSOCIATED CONTENT}

Supporting Information. Experimental part (procedures and spectral data). CIF files for the crystallographic structures of $\mathbf{1}$, $\mathbf{5}$ and $\mathbf{8 Z n}^{{ }^{\mathbf{O A c}}{ }_{\mathrm{NH}} \mathbf{B u} \cdot \mathbf{H}^{+}, \mathbf{O T f}-(\mathrm{CCDC} \text { numbers } 1560725,1560726}$ and 1560727). This material is available free of charge via the Internet at http://pubs.acs.org.

\section{AUTHOR INFORMATION}

\section{Corresponding Author}

*stephane.legac@univ-rennes1.fr; bernard.boitrel@univrennes1.fr.

\section{ACKNOWLEDGMENT}

Dr. Cédric Fischmeister is deeply acknowledged for his help in the hydrogenation reaction. We are grateful to the Ministère de l'Enseignement Supérieur et de la Recherche and to the Agence Nationale de la Recherche for financial support (ANR research program PRALLOCAT, ANR-16-CE07-0014).

\section{REFERENCES}

1 For general reviews, see: (a) Sessler, J. L.; Seidel, D. Angew. Chem. Int. Ed. 2003, 42, 5134-5175. (b) Yoon, Z. S.; Osuka, A.; Kim, D. Nat. Chem. 2009, 1, 113-122. (c) Shin, J.-Y.; Kim, K. S.; Yoon, M.C.; Lim, J. M.; Yoon, Z. S.; Osuka, A.; Kim, D. Chem. Soc. Rev. 2010, 39, 2751-2767. (d) Stępień, M.; Sprutta, N.; Latos-Grażyński, L. Angew. Chem. Int. Ed. 2011, 50, 4288-4340. (e) Saito, S.; Osuka, A. Angew. Chem., Int. Ed. 2011, 50, 4342-4373. (f) Osuka, A.; Saito, S. Chem. Commun. 2011, 47, 4330-4339. (g) Roznyatovskiy, V. V.; Leeb, C.H.; Sessler, J. L. Chem. Soc. Rev. 2013, 42, 1921-1933. (h) Tanaka, T.; Osuka, A. Chem. Rev. 2017, 117, 2584-2640. (i) Mo Sung, Y.; Oh, J.; Cha, W.-Y.; Kim, W.; Min Lim, J.; Yoon, M.-C.; Kim, D. Chem. Rev. 2017, 117, 2257-2312. (j) Szyszko, B.; Białek, M. J.; PacholskaDudziak, E.; Latos-Grażyński, L. Chem. Rev. 2017, 117, 2839-2909.

2 Selected leading references: (a) Stępień, M.; Latos-Grażyński, L.; Sprutta, N.; Chwalisz, P.; Szterenberg, L. Angew. Chem. Int. Ed. 2007, 46, 7869-7873. (b) Sankar, J.; Mori, S.; Saito, S.; Rath, H.; Suzuki, M.; Inokuma, Y.; Shinokubo, H.; Kim, K. S.; Yoon, Z. S.; Shin, J.Y.; Lim, J. M.; Matsuzaki, Y.; Matsushita, O.; Muranaka, A.; Kobayashi, N.; Kim, D.; Osuka, A. I. Am. Chem. Soc. 2008, 130, 1356813579. (c) Park, J. K.; Yoon, Z. S.; Yoon, M.-C.; Kim, K. S.; Mori, S.; Shin, J.-Y.; Osuka, A.; Kim, D. I. Am. Chem. Soc. 2008, 130, 1824-1825. (d) Tanaka, Y.; Saito, S.; Mori, S.; Aratani, N.; Shinokubo, H.; Shibata, N.; Higuchi, Y.; Yoon, Z. S.; Kim, K. S.; Noh, S. B.; Park, J. K.; Kim, D.; Osuka, A. Angew. Chem., Int. Ed. 2008, 47, 681-684. (e) Saito, S.; Shin, J.-Y.; Lim, J. M.; Kim, K. S.; Kim, D.; Osuka, A. Angew. Chem., Int. Ed. 2008, 47, 9657-9660. (f) Yoon, Z. S.; Osuka, A.; Kim, D. Nat. Chem. 2009, 1, 113-122. (g) Lim, J. M.; Shin, J.-Y.; Tanaka, Y.; Saito, S.; Osuka, A.; Kim, D. L. Am. Chem. Soc. 2010, 132, 3105-3114. (h) Tanaka, T.; Osuka, A. Möbius aromatic and antiaromatic expanded porphyrins. In Chemical Science of $\pi$ Electron Systems; Springer: Tokyo, 2015; pp 257-272.

3 (a) Heilbronner, E. Tetrahedron Lett. 1964, 5, 1923-1928. (b) Ajami, D.; Oeckler, O.; Simon, A.; Herges, R. Nature 2003, 426, 819-821. (c) Castro, C.; Chen, Z. ; Wannere, C. S.; Jiao, H.; Karney, W. L.; Mauksch, M.; Puchta, R.; van Eikema Hommes, N. J. R.; von Ragué Schleyer, P. L. Am. Chem. Soc. 2005, 127, 2425-2432. (d) Rzepa, H. S. Chem. Rev. 2005, 105, 3697-3715. (e) Herges, R. Chem. Rev. 2006, 106, 4820-4842.

4 (a) Sessler, J. L.; Davis, J. M. Acc. Chem. Res. 2001, 34, 989-997. (b) Seidel, D.; Lynch, V.; Sessler, J. L.Angew. Chem., Int. Ed. 2002, 41, 1422-1425. (c) Eller, L. R.; Stępień, M.; Fowler, C. J.; Lee, J. T.; Sessler, J. L.; Moyer, B. A. J. Am. Chem. Soc. 2007, 129, 11020-11021. (d) Sessler, J. L.; Karnas, E.; Sedenberg, E. In Porphyrins and Expanded Porphyrins as Receptors, in Supramolecular Chemistry: From Molecules to Nanomaterials. Steed, J. W.; Gale, P. Eds; John Wiley \& Sons: Chichester, 2012. (e) Zhang, Z.; Kim, D. S.; Lin, C.-Y.; Zhang, H.; Lammer, A. D.; Lynch, V. M.; Popov, I.; Miljanić, O. Š.; Anslyn, E. V.; Sessler, J. L. L.Am. Chem. Soc. 2015, 137, 7769-7774. 
5 Core Concepts in Supramolecular Chemistry and Nanochemistry, Jonathan W. Steed, David R. Turner, Karl J. Wallace, John Wiley \& Sons, Chichester, England, 2007.

6 Ménand, M.; Sollogoub, M.; Boitrel, B.; Le Gac, S. Angew. Chem., Int. Ed. 2016, 55, 297-301.

7 Le Gac, S.; Boitrel, B.; Sollogoub, M.; Ménand, M. Chem. Commun. 2016, 52, 9347-9350.

8 (a) Suzuki, M.; Osuka, A. L.Am. Chem.Soc. 2007, 129, 464-465. (b) Suzuki, M.; Osuka, A. Angew. Chem. Int. Ed. 2007, 46, 51715174. (c) Yoon, M.-C.; Cho, S.; Suzuki, M.; Osuka, A.; Kim, D. L. Am. Chem. Soc. 2009, 131, 7360-7367.

9 Yoneda, T.; Kim, T.; Soya, T.; Neya, S.; Oh, J.; Kim, D.; Osuka, A. Chem. Eur. I. 2016, 22, 4413-4417.

10 (a) Youfu, K.; Osuka, A. Tetrahedron Lett. 2006, 47, 1381-1384. (b) Mori, S.; Kim, K. S.; Yoon, Z. S.; Noh, S. B.; Kim, D.; Osuka, A. L.Am. Chem. Soc. 2007, 129, 11344-11345. (c) Tanaka, T.; Osuka, A. Chem. - Eur. I. 2012, 18, 7036-7040. (d) Yoneda, T.; Aratani, N.; Osuka, A. L. Porphyrins Phthalocyanines 2013, 17, 665-672. (e) Suzuki, M.; Hoshino, T.; Neya, S. Orq. Lett. 2014, 16, 327-329.

11 (a) Youfu, K.; Osuka, A. Org. Lett. 2005, 7, 4381-4384. (b) Inoue, M.; Yoneda, T.; Youfu, K.; Aratani, N.; Osuka, A. Chem. - Eur. I. 2011, 17, 9028-9031.

12 (a) Suzuki, M.; Shimizu, S.; Shin, J.-Y.; Osuka, A. Tetrahedron Lett. 2003, 44, 4597-4601. (b) Figueira, F.; Farinha, A. S. F.; Tomé, A. C.; Cavaleiro, J. A. S.; Almeida Paz, F. A.; Tomé, J. P. C. J. Porphyrins Phthalocvanines 2014, 18, 824-831. (c) Figueira, F.; Farinha, A. S. F.; Muteto, P. V.; Polêto, M. D.; Verli, H.; Gomes, M. T. S. R.; Tomé, A. C.; Cavaleiro, J. A. S.; Tomé, J. P. C. Chem. Commun. 2016, 52, 2181-2184.

13 Mori, G.; Shinokubo, H.; Osuka, A. Tetrahedron Lett. 2008, 49, 2170-2172.

14 (a) Collman, J. P.; Gagne, R. R.; Halbert, T. R.; Marchon, J. C.; Reed, C. A. L.Am. Chem. Soc. 1973, 95, 7868-7870. (b) Collman, J. P.; Gagne, R. R.; Reed, C.; Halbert, T. R.; Lang, G.; Robinson W. T. I. Am. Chem. Soc. 1975, 97, 1427-1439. (c) Lindsey, J. L. Org. Chem. 1980, 45, 5215 .

15 (a) Collman, J. P. Acc. Chem. Res. 1977, 10, 265-272. (b) Momenteau, M.; Reed, C. A. Chem. Rev. 1994, 94, 659-698. (c) Ricard, D.; Andrioletti, B.; L'Her, M.; Boitrel, B. Chem. Commun. 1999, 15231524. (d) Collman, J. P.; Boulatov, R.; Sunderland, C. J.; Fu, L. Chem. Rev. 2004, 104, 561-588. (e) Kim, E.; Chufan, E. E.; Kamaraj, K.; Karlin, K. D. Chem. Rev. 2004, 104, 1077-1133. (f) Hijazi, I.; Roisnel, T.; Even-Hernandez, P.; Furet, E.; Halet, J.-F.; Cador, O.; Boitrel, B. L.Am. Chem. Soc. 2010, 132, 10652-10653.

16 (a) Groves, J. T.; Nemo, T. E. I. Am. Chem. Soc. 1983, 105, 57865791. (b) Mansuy, D.; Battioni, P.; Renaud, J.-P.; Guerin, P. L. Chem. Soc., Chem. Commun. 1985, 155-156. (c) Boitrel, B.; Baveux-Chambenoit, V.; Richard, P. Eur. I. Inorg. Chem. 2002, 1666-1672. (d) Rose, E.; Andrioletti, B.; Zrig, S.; Quelquejeu-Ethève, M. Chem. Soc. Rev. 2005, 34, 573-583. (e) Intrieri, D.; Le Gac, S.; Caselli, A.; Rose, E.; Boitrel, B.; Gallo, E. Chem. Commun. 2014, 50, 1811-1813. (f) Carminati, D. M.; Intrieri, D.; Caselli, A.; Le Gac, S.; Boitrel, B.; Toma, L.; Legnani, L.; Gallo, E. Chem. Eur. I. 2016, 22, 13599-13612.

17 (a) Motreff, N.; Le Gac, S.; Luhmer, M.; Furet, E.; Halet, J.-F.; Roisnel, T.; Boitrel, B. Angew. Chem. Int. Ed. 2011, 50, 1560-1564. (b) Le Gac, S.; Najjari, B.; Fusaro, L.; Roisnel, T.; Dorcet, V.; Luhmer, M.; Furet, E.; Halet, J.-F.; Boitrel, B. Chem. Commun. 2012, 48, 37243726. (c) Najjari, B.; Le Gac, S.; Roisnel, T.; Dorcet, V.; Boitrel, B. L. Am. Chem. Soc. 2012, 134, 16017-16032. (d) Le Gac, S.; Najjari, B.; Dorcet, V.; Roisnel, T.; Fusaro, L.; Luhmer, M.; Furet, E.; Halet, J.-F.; Boitrel, B. Chem. Eur. I. 2013, 19, 11021-11038. (e) Le Gac, S.; Fusaro, L.; Dorcet, V.; Boitrel, B. Chem. Eur. I. 2013, 19, 1337613386. (f) Le Gac, S.; Fusaro, L.; Roisnel, T.; Boitrel, B. L. Am. Chem. Soc. 2014, 136, 6698-6715. (g) Ndoyom, V.; Fusaro, L.; Dorcet, V.; Boitrel, B.; Le Gac, S. Angew. Chem. Int. Ed. 2015, 54, 3806-3811. (h) Ndoyom, V.; Fusaro, L.; Roisnel, T.; Le Gac, S.; Boitrel, B. Chem.
Commun. 2016, 52, 517-520. (i) Le Gac, S.; Boitrel, B. New. I. Chem. 2016, 40, 5650-5655.

18 Such dressing in the "third dimension" is scarce with expanded porphyrins. Nitrogen containing ligands such as pyridyl, 5formyl-2-pyrryl and imidazolyl have been introduced at meso positions of hexaphyrins and octaphyrins. In some metal complexes, these groups participate to the coordination sphere of the metals, see: (a) Mori, H.; Sung, Y. M.; Lee, B. S.; Kim, D.; Osuka, A. Angew. Chem. Int. Ed. 2012, 51, 12459-12463. (b) Naoda, K.; Mori, H.; Oh, J.; Park, K. H.; Kim, D.; Osuka, A. L. Org. Chem. 2015, 80, 11726-11733. (c) Mori, H.; Osuka, A. Chem. Eur. I. 2015, 21, 7007-7011.

19 Suzuki, M.; Osuka, A. Org. Lett. 2003, 5, 3943-3946.

20 Hexaphyrins bearing electron withdrawing or sterically hindered substituents at meso positions turn to be more stable, see ref 19.

21 Cho, S.; Yoon, Z. S.; Kim, K. S.; Yoon, M.-C.; Cho, D.-G.; Sessler, J. L.; Kim D. L. Phys. Chem. Lett. 2010, 1, 895-900.

22 Distance of Me-tren (13 atom mean plane) to hexaphyrin (36 atom centroid) $=3.536 \AA$.

23 UV-vis absorption spectra were recorded at all steps of the NMR complexation study (Figure 6b-d), and this study was also performed at UV-vis concentration. In both cases, addition of $\mathrm{Zn}(\mathrm{OTf})_{2}$ to $\mathbf{8}$ did not afford clear optical signatures, $\mathrm{Zn}$ (II) complexation being always incomplete. These NMR and spectroscopic data suggest the formation of labile $\mathrm{Zn}$ (II) complex(es) of $\mathbf{8}$, not yet determined.

24 Protons in $\alpha$ and $\beta$ positions relative to the nitrogen atom are indeed shielded by 1.12 and 0.44 ppm (SI). Although the exo-coordination of $\mathrm{BuNH}_{2}$ orients the alkyl chain outwards, a shielding environment may arise from the two surrounding aromatic moieties Ar3 and Ar5 (Scheme 3).

25 In these conditions, 1 equiv. of TBAOTf and 1 equiv. of TfOH are formed upon $\mathrm{Zn}$ (II) metallation.

26 The protonated and neutral complexes are in a fast exchange regime on the NMR time scale at $298 \mathrm{~K}$. Slow exchange regime was observed at low temperature, i.e. $230 \mathrm{~K}$.

27 For a recent clarification of the term «allostery », see : von Krbek, L. K. S.; Schalley, C. A.; Thordarson P. Chem. Soc. Rev. 2017, 46, 2622-2637.

28 Kovbasyuk, L.; Krämer, R. Chem. Rev. 2004, 104, 3161-3188.

$29 \mathrm{Ge}(\mathrm{IV})$ Möbius hexaphyrin complexes with a single exogeneous phenoxide ligand have been described recently, see: Izawa, M.; Kim, T.; Ishida, S.-i.; Tanaka, T.; Mori, T.; Kim, D.; Osuka, A. Angew. Chem. Int. Ed. 2017, 56, 3982-3986.

$30 \Pi=\prod_{i} \cos \theta_{\mathrm{i}}, \theta_{\mathrm{i}}$ being the torsional angles along the SMC. The resonance integral between two adjoining carbon $\mathrm{sp}^{2}$ centers is assumed to scale with $\cos \theta_{\mathrm{i}}$, see ref $1 \mathrm{j}$.

31 Other popular geometric criteria of aromaticity such as HOMA are not reliable in complex polycyclic conjugated compounds and were not included in this study. See: (a) Wannere, C. S.; Sattelmeyer, K. W. ; Schaefer III, H. F.; Schleyer, P. v. R. Angew. Chem. Int. Ed. 2004, 43, 4200-4206. (b) Alonso, M.; Geerlings, P.; de Proft, F. Chem. Eur. I. 2012, 18, 10916-10928.

32 (a) Mori, S.; Shimizu, S.; Taniguchi, R.; Osuka, A. Inorg. Chem 2005, 44, 4127-4129. (b) Tanaka, Y.; Saito, S.; Mori, S.; Aratani, N.; Shinokubo, H.; Shibata, N.; Higuchi, Y.; Yoon, Z. S.; Kim, K. S.; Noh, S. B.; Park, J. K.; Kim, D.; Osuka, A. Angew. Chem. Int. Ed. 2008, 47, 681-684.

33 Ishida, S.-i.; Tanaka, T.; Lim, J. M.; Kim, D.; Osuka, A. Chem. Eur. L. 2014, 20, 8274-8278.

34 Higashino, T.; Inoue, M.; Osuka, A. L. Org. Chem. 2010, 75, 7958-7961.

35 Tokuji, S.; Shin, J.-Y.; Kim, K. S.; Lim, J. M.; Youfu, K.; Saito, S.; Kim, D.; Osuka, A. I. Am. Chem. Soc. 2009, 131, 7240-7241.

36 Higashino, T.; Soya, T.; Kim, W.; Kim, D.; Osuka, A. Angew. Chem. Int. Ed. 2015, 54, 5456-5459. 
37 It is worth reminding that aromaticity is not a variable that can be quantified on a one-scale dimension, see: (a) Jug, K.; Köster, A. M. J. Phys. Org. Chem. 1991, 4, 163-169. (b) Cyrański, M. K.; Krygowski, T. M.; Katritzky, A. R.; Schleyer, P. v. R. I. Org. Chem. 2002, 67, 1333-1338. (c) Stanger, A. Chem. Commun. 2009, 1939-1947. For description of aromaticity in porphyrins, see: (a) Bröring, M. Angew. Chem. Int. Ed. 2011, 50, 2436-2438. (b) Wu, J. I.; Fernández, I.; Schleyer, P. v. R. L. Am. Chem. Soc. 2013, 135, 315-321.

38 (a) Tanaka, T.; Sugita, T.; Tokuji, S.; Saito, S.; Osuka, A. Angew. Chem., Int. Ed. 2010, 49, 6619-6621. (b) Mori, T.; Tanaka, T.; Higashino, T.; Yoshida, K.; Osuka, A. L. Phys. Chem. A 2016, 120, 42414248.

39 The protonation state of the tren cap of 8 has minor influence on the d.e. (Table 2, entries 6 and 7, pathways A vs. B).

40 The $\Delta \delta$ of the acetato are similar to the case of $\mathrm{AcO}-/ \mathrm{BuNH}_{2}$, indicating similar endo/exo selectivity for the coordination to zinc.
41 It is also worth to note that the $\Delta \delta$ of MBA ( $\alpha$ and $\beta$ positions relative to nitrogen atom) are markedly different to those of $\mathrm{BuNH}_{2}$ and even of opposite sign (Table 2, entries 6 vs. 1), indicating different positioning relative to the host. Hence, both the endo and exo coordination environments are sterically discriminating.

$42 \Delta \varepsilon$ values were not calculated, assessment of the accurate concentration of the optically active species being difficult by absorption spectroscopy.

43 To the best of our knowledge, the highest chiral induction for a Möbius hexaphyrin metal complex amounts to $23 \%$ enantiomeric excess, see ref 38a.

44 A quantitative measurement of the racemization barrier by means of kinetic studies was hampered by the difficulty to assess accurate concentrations of optically active species.

\section{Table of Contents artwork}

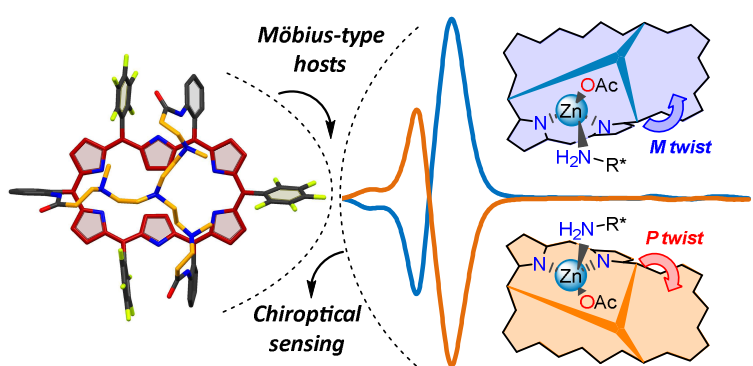

